\title{
Effect of graphite particles on physical and mechanical properties of nickel matrix composite
}

\author{
Hashim Sh. Hammood ${ }^{1}$, Amjed S. Mahmood ${ }^{2}$, Saif S. Irhayyim ${ }^{3}$ \\ ${ }^{1,3}$ Department of Mechanical Engineering, College of Engineering, Tikrit University, Iraq. \\ ${ }^{2}$ Department of electromechanical engineering, College of Engineering, University of Samarra, Iraq.
}

\section{Article Info}

Received, 2019

\section{Keyword:}

Nickel matrix composite

Powder metallurgy

Physical properties

Microhardness

Wear test

\begin{abstract}
The composite materials have effective properties and characteristics for use in most modern and important applications such as space and transportation applications, especially in internal combustion engines as well as applications and marine industries. In this study, Nickel -5 vol.\% Zirconium dioxide composites with $0,2,4,6$ and 8 vol. \% of graphite particles are prepared by powder metallurgy technique. The samples are pressed at $900 \mathrm{MPa}$ for $1 \mathrm{~min}$ after mixing the hybrid composite powders for $15 \mathrm{~min}$ by using a mechanical mixer, followed by sintering at $1160 \mathrm{oC}$ for 3 hours. The hybrid composites are characterized by using an optical microscope. The wear test under dry sliding conditions was performed under various loads of 5, 10, 15 and 20 Newton and at a fixed sliding distance of around $1810 \mathrm{~m}$. It is found that increasing graphite content results decrease in bulk and apparent densities in contrast with total porosity, apparent porosity, and water absorption. Alternatively, the increasing volume fraction of graphite particles improves the micro-hardness, diametral compressive strength and wear resistance till an optimum value up to $4 \%$, then severely reduction is observed. Whereas the wear resistance decreased by increasing the applied loads for all reinforcement content. The results, in conclusion, reveal that the hybrid composites at $4 \%$ graphite particles relatively have high mechanical and wear properties, and it could be considered a suitable because of high corrosion resistance in our daily life applications.
\end{abstract}

\section{Corresponding Author:}

Saif S. Irhayyim,

Department of Mechanical Engineering,

Tikrit University,

Salah Aldin, Tikrit, Iraq.

Email: saiof11@tu.edu.iq.

\section{Introduction}

Composite materials have active properties and characteristics for use in most modern and essential applications such as space and transportation applications, especially in internal combustion engines as well as applications and marine industries. It is challenging to obtain a single material with various properties and features that can be used in complex applications. Therefore, the composites are the solution for that [1]-[3], the composite materials consist of two main phases: the matrix and the reinforcement material. The reinforcement material gives strength and stiffness to the composites while the matrix material connects the reinforcement materials to transfer and distribute the load, in addition to protecting the composites from the external environment. Modern methods used to fabricate a composite structure are dependent upon structure configuration, material performance requirements, and production rates [4], [5]. 
Metal Matrix Composite (MMC) in which alloys or metal are combined with metallic, and the other integral part may be various metal or another material reinforcement, such as organic or ceramic material. When the composite contains more than two essential parts, or at least three materials are combined, it is called a hybrid composite. The significant advantages of MMC include superior mechanical properties, suitable wear resistance, high toughness, and low creep rate [6]-[9].

The most common method for preparing MMCs are powder metallurgy technique, which has the potential to produce a variety of microscopic structures and to obtain materials that have a collection of properties that cannot be obtained by any other techniques. Furthermore, the powder metallurgy has the possibility of manufacturing products of all metals and different type of alloys. The particle size can be controlled by this method, and the microstructure is homogeneous and relatively uniform. This method is economical and highly productive [10]-[12].

Nickel matrix composites have a high strength to weight ratio, which is suitable to use in safety for critical elements in high-value applications of modern aero engines and gas turbines of power plants [13]-[15]. Nickel reinforced with carbon materials, for instance, graphite, is called as a self-lubricating nickel matrix composite. These composites improve the tribological properties compared to unreinforced materials or reinforced with non-carbon particles. Self-lubrication defined as the material ability to transfer deposited solid lubricants, for example, graphite in the contact tribosurfaces to reduce the friction coefficient and rate of wear because the graphite material behaves as a solid lubricant [13], [16]-[18].

The damaging influence of graphite particles on mechanical properties of composites is the main challenge in fabrication nickel - graphite composites in industrial components due to the nature of graphite is brittle compared to nickel and its alloys. There are many methods for reducing the adverse influence of graphite material on the deterioration of mechanical performance. For instance, using hybrid nickel metal matrix composites, including ceramic particles as well as graphite material gives better both tribological performance and other mechanical properties compared to nickel - graphite composites. In these hybrid composites, ceramic particles possess the load-bearing ability, and graphite particles act as a solid lubricant, which leads to decrease in wear rate and improve the mechanical properties at the same time [16], [17].

Therefore, this study aims to investigate adding graphite particles on the nickel $-5 \mathrm{vol} \%$ zirconium dioxide matrix composites prepared by powder metallurgy technique, in order to provide essential information about the correlations between the graphite content and the physical, mechanical, and wear properties. This study will enable researchers to quantitatively assess the relative contributions of additives to nickel matrix composites.

\section{Materials and Methods}

\subsection{Composite preparation}

The hybrid composite samples used in this study are prepared by using a powder metallurgy technique. Nickel metal powder is used as a matrix material with particle size $\leq 53 \mu \mathrm{m}$ and $99.9 \%$ purity. Graphite and $\mathrm{ZrO}_{2}$ powders are used as reinforcement materials with particle size $\leq 63 \mu \mathrm{m}$ and $\leq 25 \mu \mathrm{m}$ respectively as well as with purity $99.8 \%$ and $99.9 \%$ respectively. Standard sieves with different grades are used to verify particles size. The reinforcement materials are dried at $200{ }^{\circ} \mathrm{C}$ for 2 hours to eliminate the moisture and other volatile substances. The volume fraction of $\mathrm{ZrO}_{2}$ powder is maintained constant of $5 \%$, and different contents of graphite powder 0, 2, 4, 6 and $8 \mathrm{vol} . \%$ is used. After that, the mixing weight of each composite is prepared by a sensitive electrical scale with an accuracy of $0.1 \mathrm{mg}$. Then the powders are mixed for 15 minutes by using a mechanical mixer. The mixture is pressed in uniaxial direction at room temperature, by using the universal testing machine type (HOYTOM), at $900 \mathrm{MPa}$ for two minutes to avoid the possibility of elastic return phenomena. The solid steel mold, with $60 \mathrm{HRC}$ and $8 \mathrm{~mm}$ diameter, is used to obtain samples of $8 \mathrm{~mm}$ diameter and $10 \mathrm{~mm}$ height, as shown in Figure 1. Subsequently, the samples are sintered at $1160{ }^{\circ} \mathrm{C}$ for 3 hours, which is gradually increased at a rate of $8{ }^{\circ} \mathrm{C} / \mathrm{min}$ followed by cooling the furnace. The process of sintering is done by putting the samples inside a ceramic pot to inhibit the sample oxidation, then covering them with graphite powder and cast iron chip as well as sealed with fire clay to prevent oxygen from reaching the sample surface [10], [19]. 

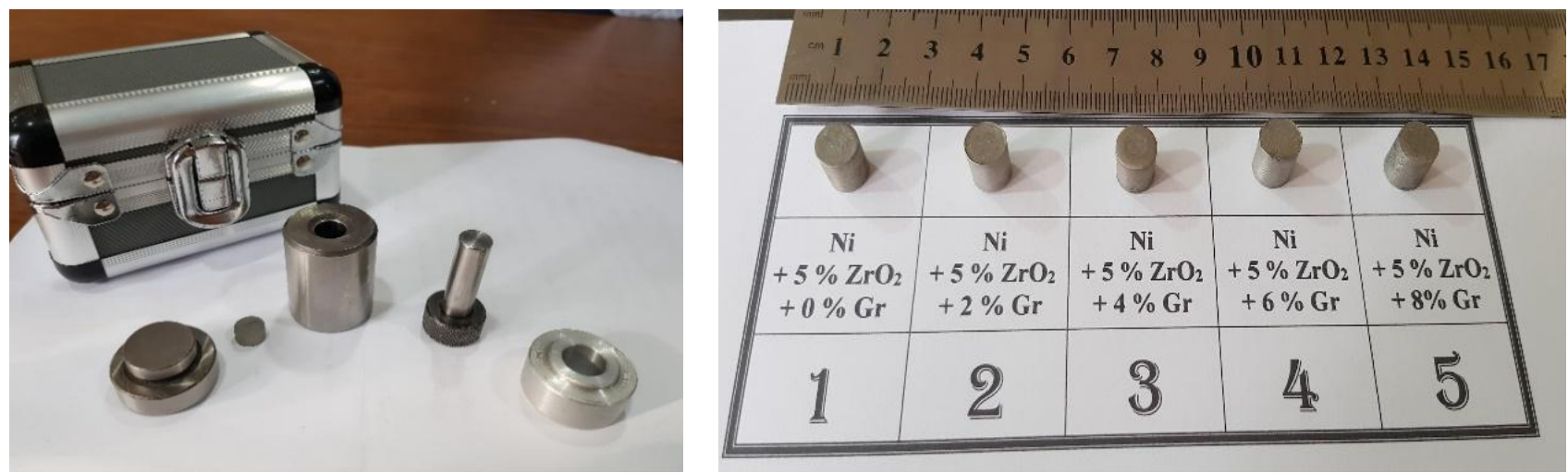

Figure 1. The mold and prepared samples according to the reinforcement ratios.

\subsection{Tests and Characterizations}

The physical properties are investigated such as bulk and apparent densities, total and apparent porosities, and water absorption by using the Archimedes principle according to ASTM C373 [6], [20], [21]. For the microscopic analysis and micro-Vickers hardness measurement, the samples are prepared by wet grinding with different paper grade 320,600, 1000, and 2500 and washing them by water and drying them. A special cloth with alumina solution conducts a polishing process. After that, the samples are washed with water and alcohol and then dried with air using samples' dryer. The optical microscope performs the microscopic examination with a camera which is connected to a computer. Next, the microhardness test is carried out by utilizing the micro-Vickers apparatus. The hardness is calculated by taking a mean value of five values for each sample. Diametral compressive strength $\left(\sigma_{c}\right)$ is performed by applying a perpendicular load on the diameter of the sample that is in a disc form, and it is calculated by the following equation [10], [22]:

$$
\sigma_{\mathrm{c}}=2 \mathrm{~T} / \pi \mathrm{LM}
$$

Where T, L, and $\mathrm{M}$ are the vertically applied load (Newton), the diameter of the sample (mm) and the thickness of the sample $(\mathrm{mm})$, respectively.

The wear test under dry sliding conditions is performed, accordance with ASTM G99 [23], by utilizing the device of wear and friction monitor (model: ED-201) with a pin on the disc as shown in Figure 2. The samples are cylindrical shapes, as mentioned above. The wear device contains a weight rack, which is used at various loads 5, 10, 15 and 20 Newton. The installed disc hardness, diameter, and rotational velocity are $62 \mathrm{HRC}, 60$ $\mathrm{mm}$, and 480 r.p.m respectively. The speed and sliding distance are maintained constant at $1.5 \mathrm{~m} / \mathrm{s}$ and 1810 $\mathrm{m}$ respectively. The surface of the disc and the sample are polished by paper with a grade of 1000 . The samples and disc are cleaned before each test with acetone. The weight loss is measured during the test period using the electrical scale. The wear rate $\left(\mathrm{W}_{\mathrm{R}}\right)$ is calculated by using the following equation [6], [23], [24]:

$$
\mathrm{W}_{\mathrm{R}}=\mathrm{N}_{1}-\mathrm{N}_{2} / \mathrm{SD}
$$

Where $\mathrm{N}_{1}$ and $\mathrm{N}_{2}$ are the weight of the tested sample before and after the test and SD is the sliding distance. Figure 3 displays the schematic diagram of the experimental procedure of this study.

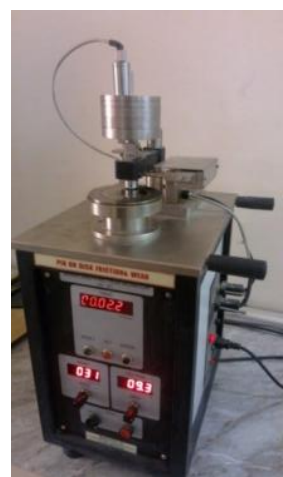

Figure 2. Wear and friction monitor ED-201 with a pin on the disc. 


\section{Results and Discussion}

\subsection{Microstructural Characterization}

Figure 4 illustrates optical microstructure images of the hybrid composite with different graphite content. Because of the vast difference between the nickel and graphite densities, the high contrast of the micrographs can be observed. Furthermore, it could be noticed bright particles of the nickel matrix and black irregular regions of graphite particles and porosities. It could be concluded from the microstructure images that the well bonded is existed between the nickel particles due to the pressing and sintering process. The graphite material is uniformly distributed and bonded well with the nickel matrix. A partly clustering and agglomeration in composites with high graphite content cause a decrease in the uniformity and homogeneity of the samples. One could observe increasing porosity content by improving the content graphite particles.

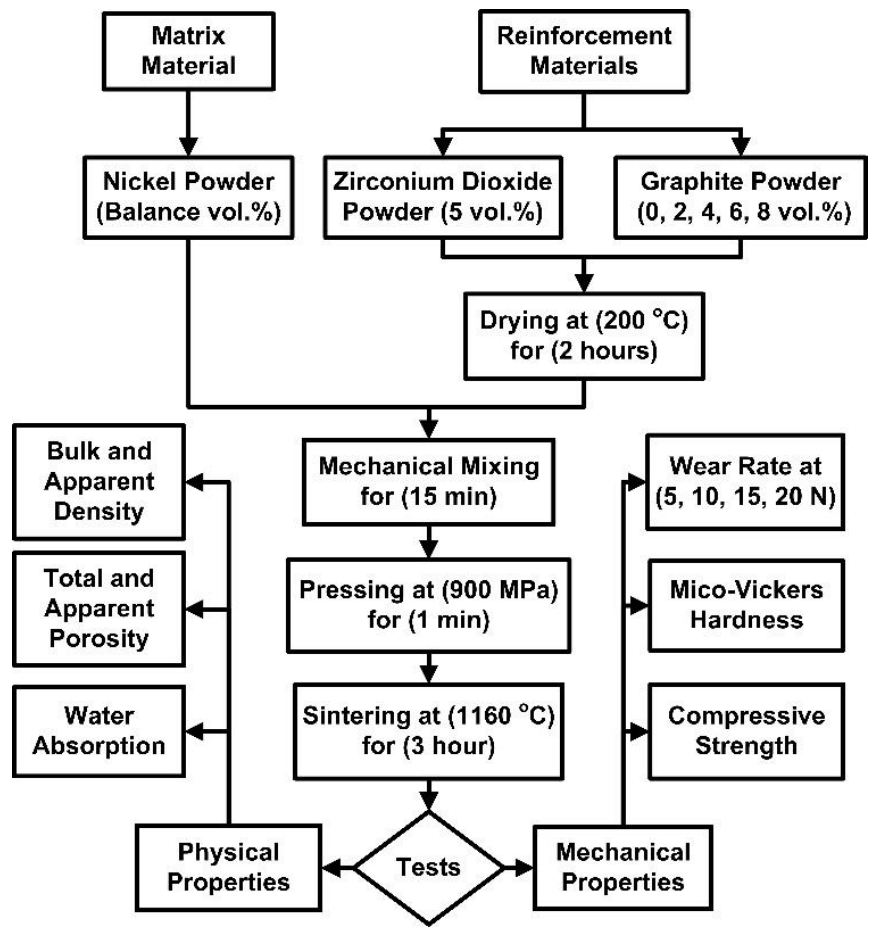

Figure 3. The schematic diagram for the experimental procedure of the hybrid composite.

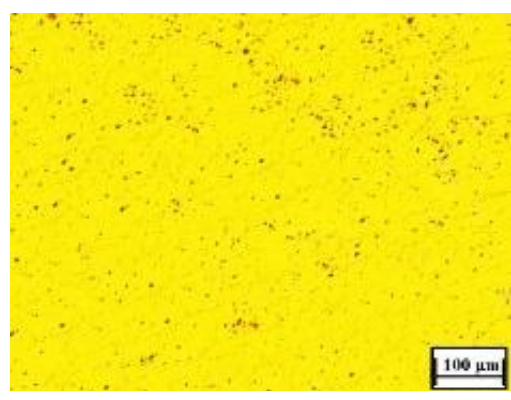

(a)

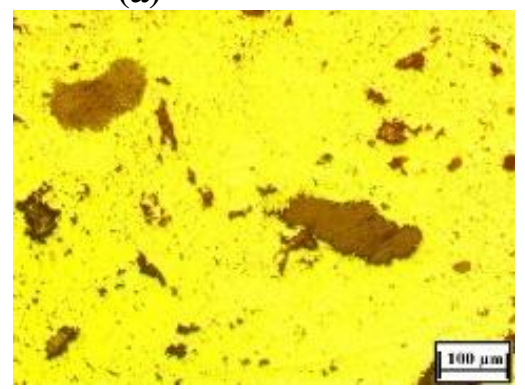

(d)

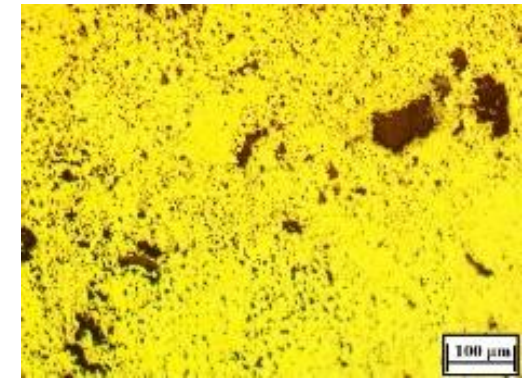

(b)

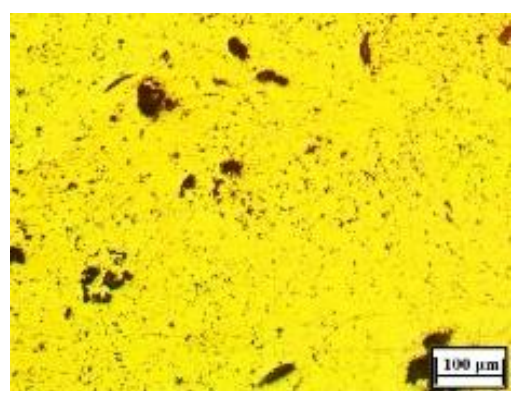

(c)

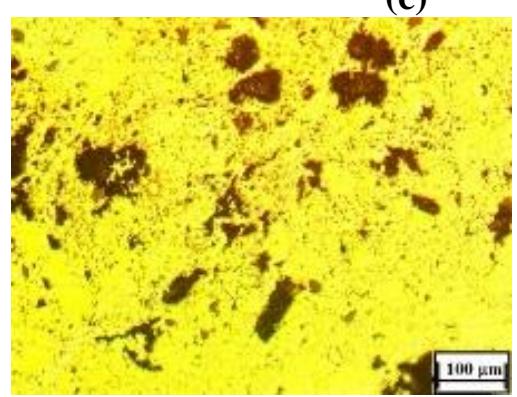

(e)

Figure 4. Optical microstructure images of the hybrid composite produced with 
(a) $0 \%$ Gr (b) $2 \%$ Gr (c) $4 \%$ Gr (d) $6 \%$ Gr (e) $8 \%$ Gr.

\subsection{Physical Properties}

Figure 5, 6, and 7 present the influence of graphite content on different physical properties of the hybrid composite. As can be seen, there was a decreasing in the bulk and apparent densities and increasing the total and apparent porosities and water absorption of the hybrid composites with the increasing of the graphite content. This expected behavior can be associated with the low density of graphite material $(2.26 \mathrm{~g} / \mathrm{cm} 3)$ [25] compared with the other hybrid composite compounds thus any increase in graphite particles will decrease both the bulk and apparent densities. Furthermore, the porosity of the hybrid composite is increased with enhancing in the graphite content as shown in Figure 4. Also, the presence of graphite particles works to decrease both densification and volume shrinkage and stop the complete consolidation of the composite matrix during sintering. This effect keeps closed porosity in their position; all these parameters lead to an increase in the apparent porosity, water absorption and total porosity with the graphite content as shown in Figures 6 and 7, which is found by previous studies [18], [26] for aluminum matrix composite by increasing the graphite content.

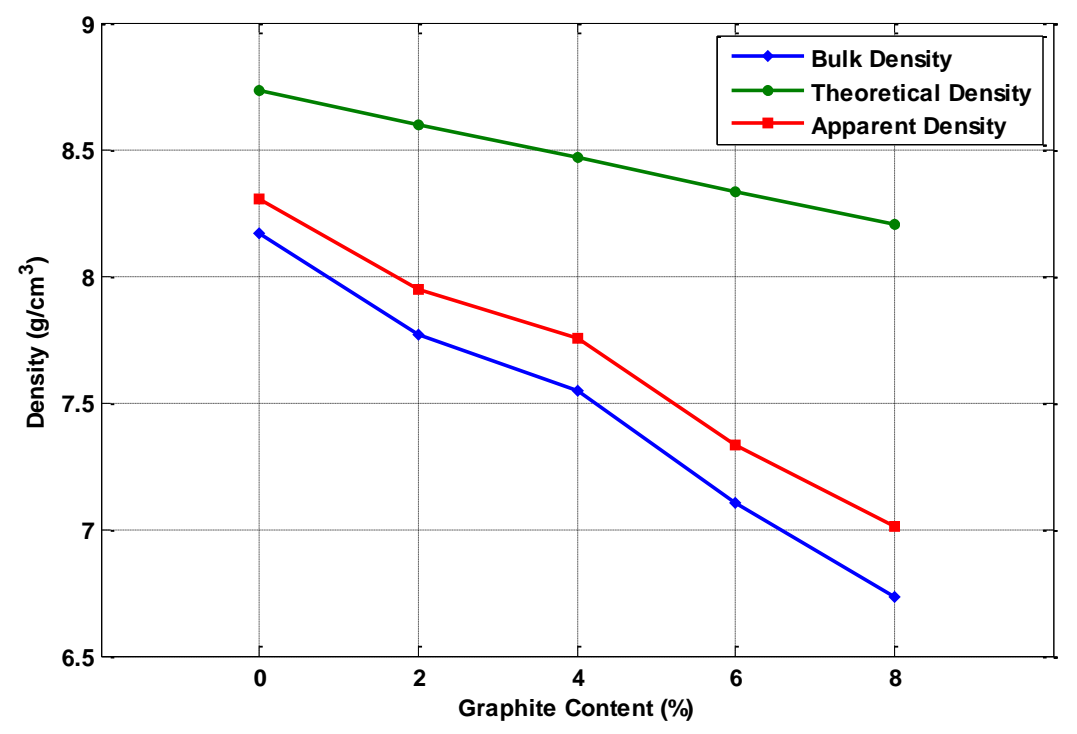

Figure 5. The relationships between the densities with graphite content.

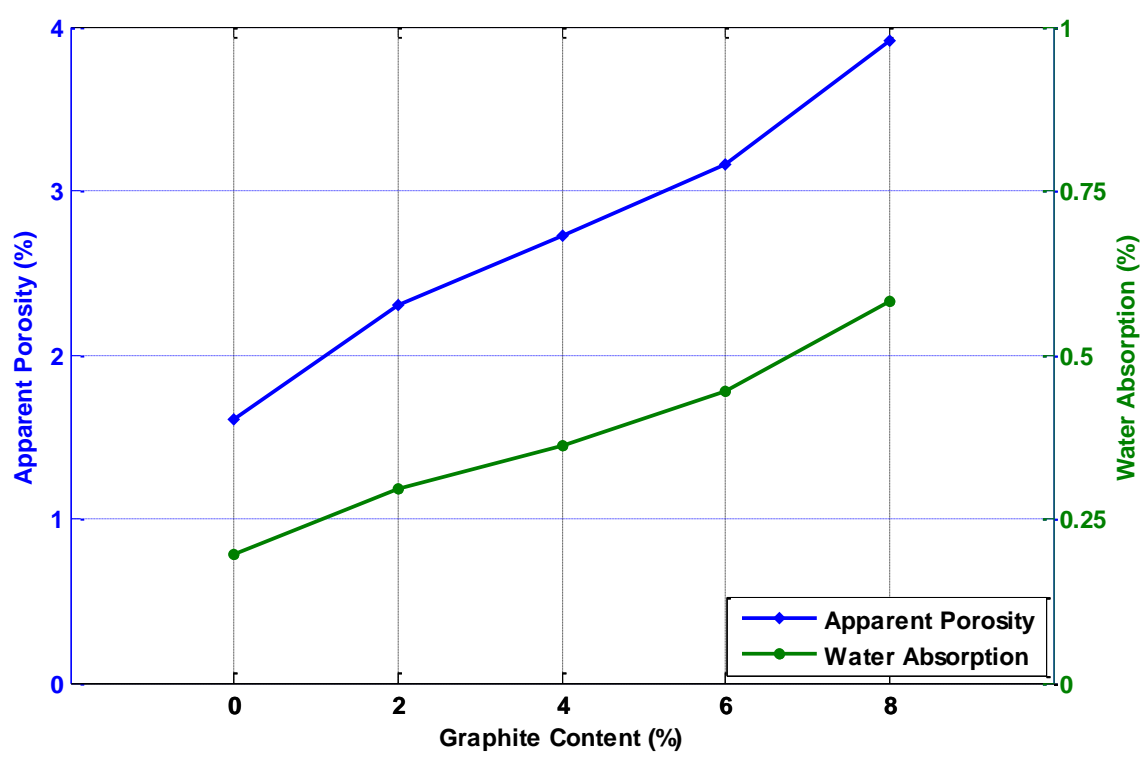

Figure 6 . The relationship between the apparent porosity and water absorption versus the graphite content. 


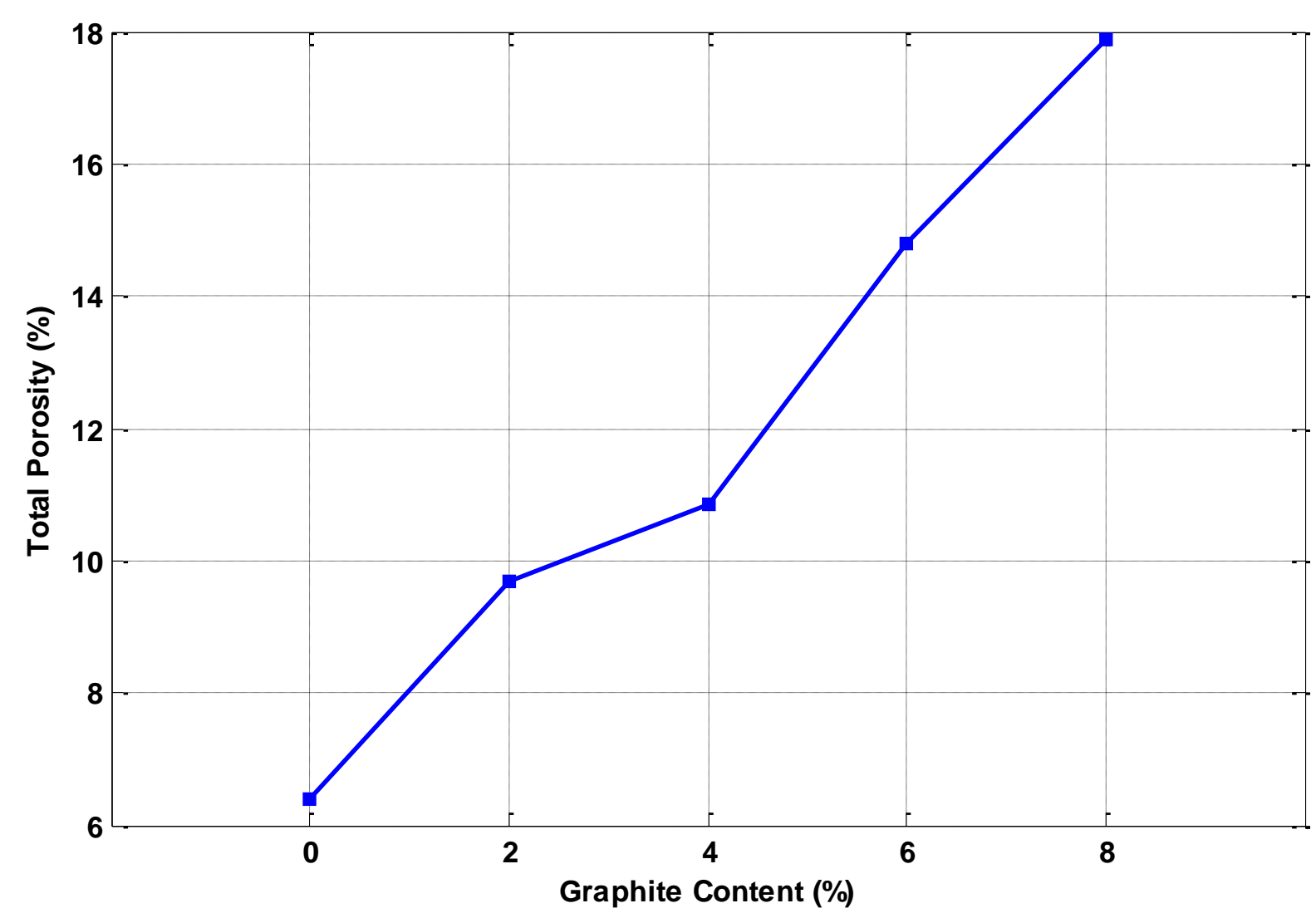

Figure 7. The relationship between the total porosity with graphite content.

\subsection{Microhardness and Diametral Compressive Strength Tests}

The correlation between the volume fraction of graphite particles and both microhardness and diametral compressive strength are demonstrated in figures 8 and 9. It can be observed that the microhardness and compressive strength enhanced by increasing the graphite content up to 4 vol.\% and reaches higher values then decreased rapidly. It is ambiguous behavior that the hardness and compressive strength values increase with increasing graphite content up to 4 vol.\%. This abnormal behavior requests more investigation due to the brittle nature of graphite that causes deterioration in mechanical properties. Similar results were found previously by Sundriyal et al. [27] who found that the maximum hardness and compressive strength were achieved at $4 \%$ graphite content for aluminum matrix composites and then reduced.

The reduction behavior in hardness and compressive strength between 4 to 8 vol.\% graphite content is attributed to the decreases in bulk density and raise in total porosity as displayed in Figures 5 and 7, due to the porosities will be a central location for concentration of stresses and caused severe reduction in mechanical properties. Moreover, it is well accepted and known that increasing the content of the soft and brittle nature of graphite particles, which quickly tends the composites to deform plastically so must result in a decrease of the hybrid composite mechanical properties. On the other hand, the decreasing inhomogeneity distribution as mentioned above in 'Microstructural characterization' part that due to clustering and agglomeration behavior of graphite particles in some reigns during the sintering process led to high porosity at the high content of graphite. These regions will be stayed constant, causing the weak binding agent between the matrix materials and led to a further reduction in microhardness and compressive strength of the composites. Similar findings can be observed in the literature [26], [28], [29] for the aluminum matrix composite with increasing the graphite content. 


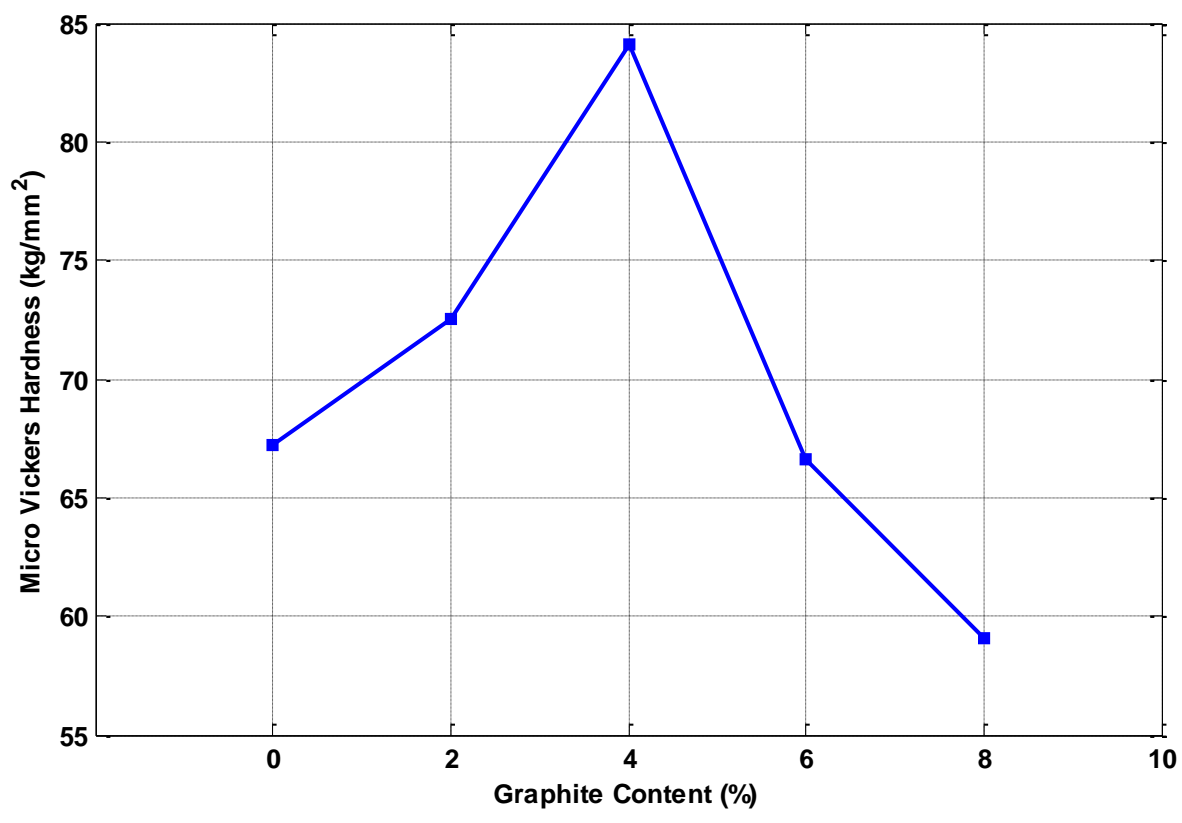

Figure 8. The relationship between the micro-Vickers hardness with graphite content.

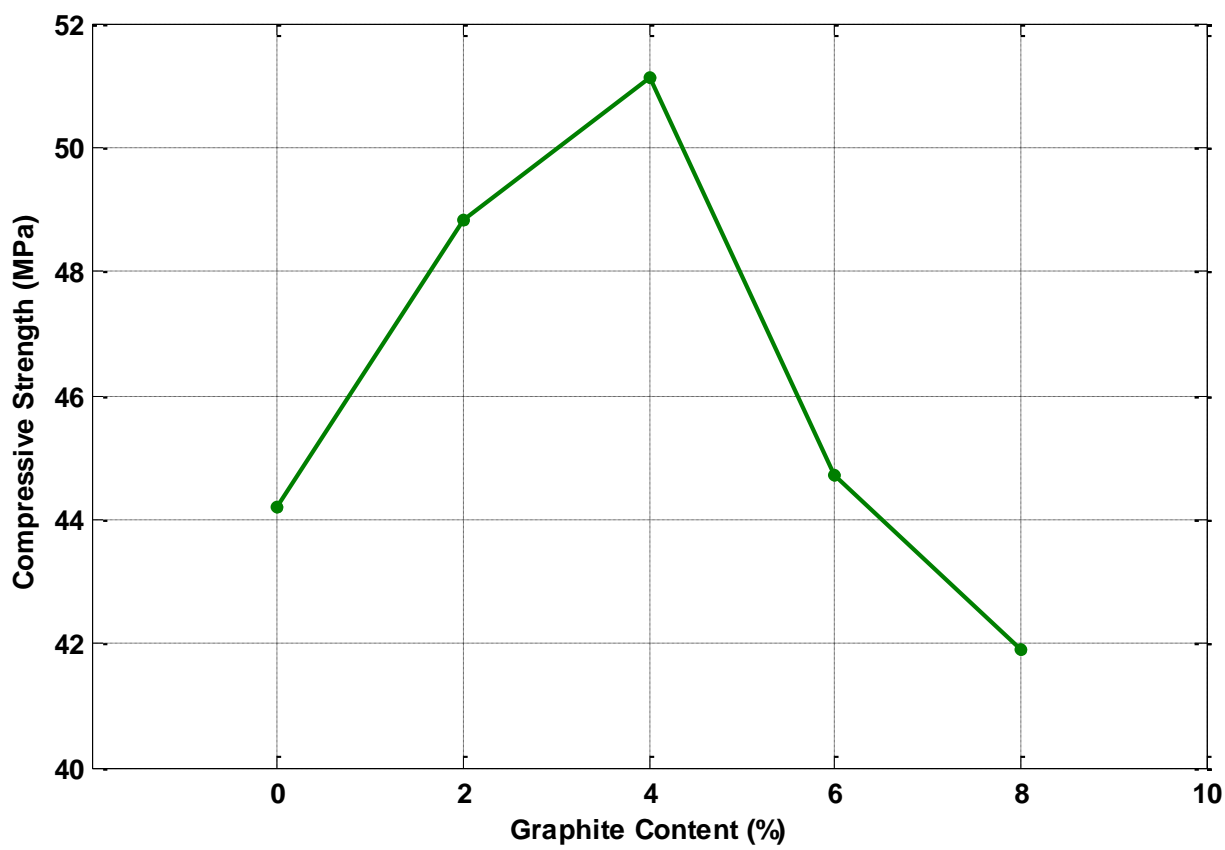

Figure 9. The relationship between the compressive strength with graphite content.

\subsection{Dry Sliding Wear Test}

\subsubsection{Effect of graphite content on the wear rate}

The influence of graphite content on the wear rate of composites at different applied loads is presented in Figure 10. It is observed that the wear rate reduced by increasing the graphite content up to 4 vol.\%, which exhibits the superior wear performance and then increased. The efficiency of graphite solid lubrication in hybrid composites depends on some factor, for instance, wear testing conditions and mainly the applied load. Besides, the shape, the size, the morphology and the distribution of graphite particles as well as the interfacial bonding between the graphite particles and the matrix materials. The reduction behavior in wear rate is generally expected and can be attributed to the following three factors: 
1. The presence of graphite particles performs a tinny lubricant film/layer between the copulating tribosurfaces. This layer will reduce the metal to metal interaction with an increase in the volume fraction of graphite particles due to increases the thickness of the lubricant film, which caused a reduction in shear stress.

2. As shown in Figure 8 the micro-hardness increased with increasing the graphite content up to 4 vol. $\%$, which will be caused a reduction in wear rate accordance with Archard's law [10], [22], [30] due to increasing the composite resistance to the wear rate.

3. The microstructure analysis images in Figure 4 shows the uniform distribution reasonably of graphite particles within the matrix materials up to 4 vol.\% as well as the sufficient bonding between the compounds phases, which increased the wear performance of the composites.

Above $4 \%$ of graphite content, the wear behavior was correctly reversed in its behavior for all applied loads. This behavior can be associated with the decreasing in the composite hardness after 4 vol.\% as displayed in Figure 8 due to the wear rate inversely proportional with the composite hardness accordance with Archard's law. Furthermore, the significant decrease in bulk density and a considerable improvement in total porosity as presented in Figures 5 and 7, respectively, will produce increases in wear rate because of the affecting a weak bonding between the hybrid composite particles. Moreover, above $4 \%$ graphite content, the hybrid composite becomes much softer. During the wear process, the wear debris will be rich in Zirconium dioxide particles that caused increasing the wear rate due to the hard particles stuck on the steel disc and enhanced the removing of hybrid composite particles because it represented as stress concentrators. Similar results were found previously by Zeren et al. [26] and Prashant et al. [28] who found that the minimum wear rate was achieved at $6 \%$ graphite content for aluminum matrix composites. Sharma et al. [29] noticed that the wear rate decreased up to $4 \%$ graphite content for Al6160 matrix composite and then increased rapidly.

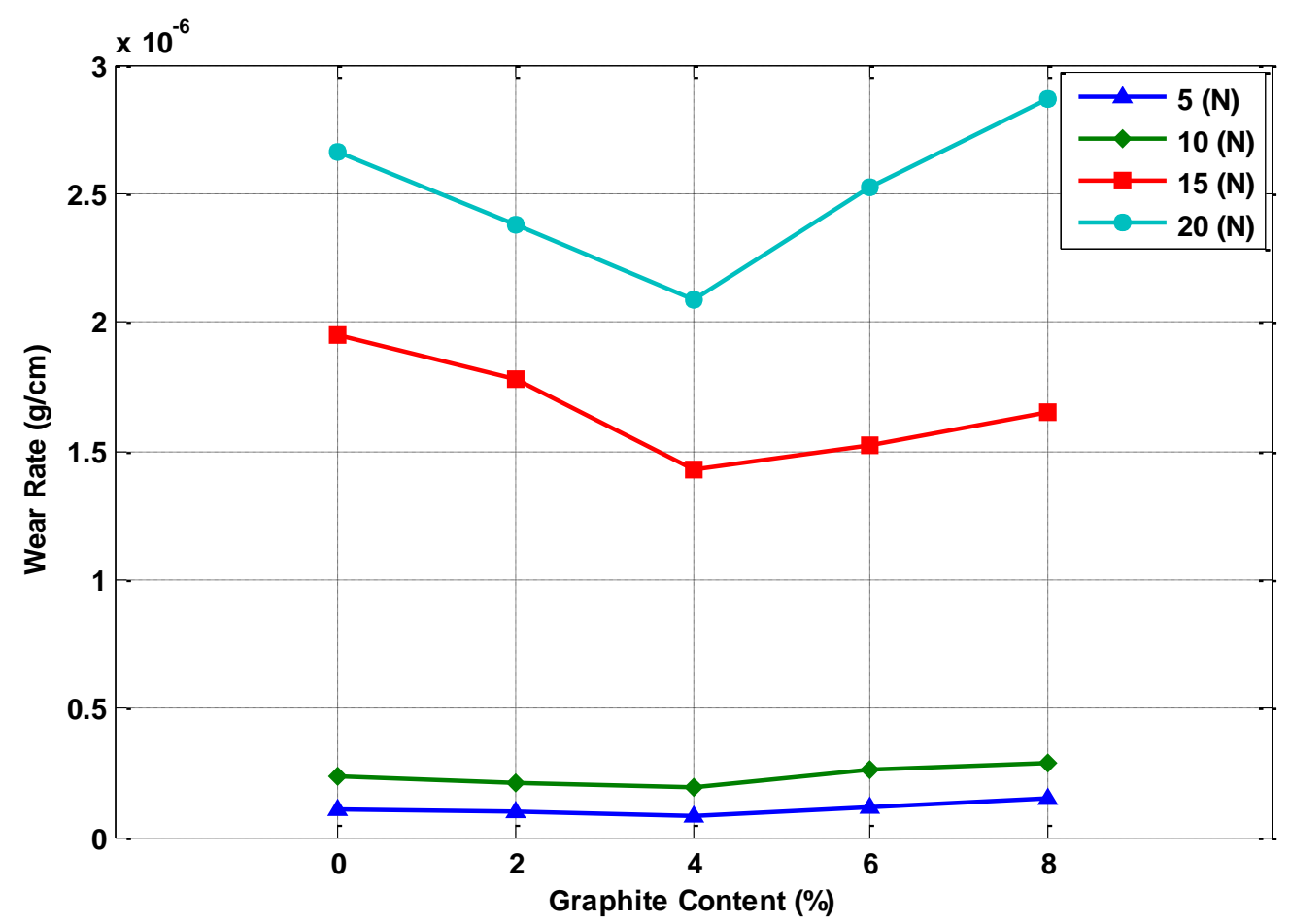

Figure 10. The relationship between the wear rate and graphite content.

\subsubsection{Effect of Applied Loads on Wear Rate}

The relation between the wear rate and applied loads for all reinforcement content is displayed in Figure 11. It is observed that severe delamination occurred in wear rate with an improvement in applied loads for all content of graphite. The rises in wear rate are generally expected accordance with Archard's law. The increasing in applied loads must cause high friction and contact between the tribosurfaces and working to accelerate the deformation of the composites due to frictional and compressive forces that controlled in dry sliding. 


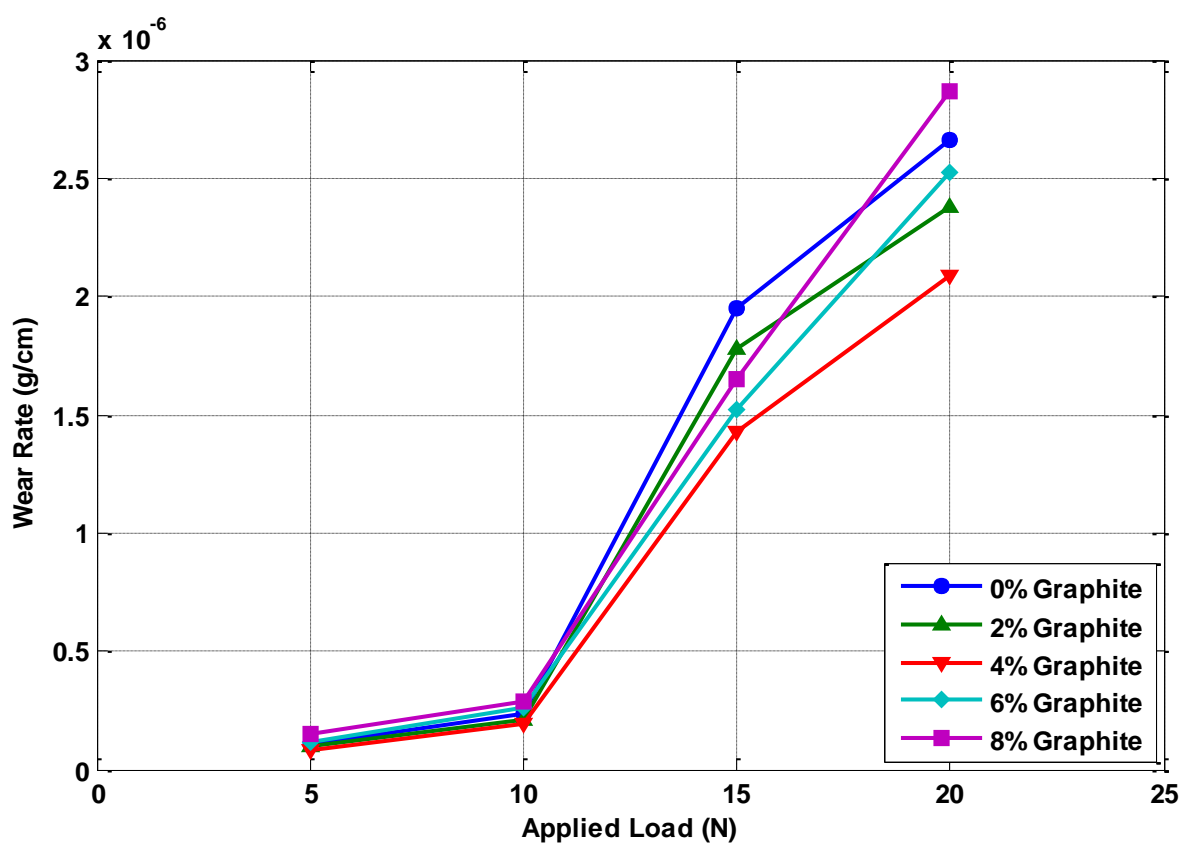

Figure 11. The relationship between the wear rate and applied load.

\section{Conclusion}

In the present experimental study, several outcomes and conclusions have been obtained from the results which could be reported as follow;

1. Nickel -5 vol.\% Zirconium dioxide composite successfully reinforced with different content of graphite particles through traditional powder metallurgy technique.

2. Optical micrographs of the hybrid composite show that graphite particles distributed uniformly in the matrix of the composite with partly agglomeration and clustering are observed after 4 vol.\% graphite content.

3. The bulk and apparent densities decreased in contrary to the total and apparent porosities, and water absorption which increased by increasing the graphite content of the hybrid composites

4. The mechanical properties represented by microhardness and compressive strength improved by increasing in the graphite content up to $4 \%$ and then decreased rapidly.

5. A significant decrease in wear rate for all applied loads was produced from increasing the graphite content up to $4 \%$ and then increased. Also, a significant increase in wear rate for all graphite content is observed by increasing the applied loads.

6. From the results mentioned above, it is concluded that Nickel with 5 vol. \% Zirconium dioxide and 4 vol. \% of graphite hybrid composite have relatively optimum wear and mechanical properties which is considered suitable in high corrosion resistance of our daily life applications.

\section{References}

[1] F. M. Mahdi, R. N. Razooqi, and S. S. Irhayyim, "Effect of graphite content and milling time on physical properties of Copper-Graphite composites prepared by powder metallurgy route," Australian Journal of Basic and Applied Sciences, vol. 7, pp. 245-255, 2013.

[2] A. Erklĭg, N. F. Doğan, and M. Bulut, "Charpy Impact Response of Glass Fiber Reinforced Composite with Nano Graphene Enhanced Epoxy," Periodicals of Engineering and Natural Sciences, vol. 5, 2017.

[3] Ö. Y. Bozkurt, Ö. Özbek, and A. R. Abdo, "The Effects of Nanosilica on Charpy Impact Behavior of Glass/Epoxy Fiber Reinforced Composite Laminates," Periodicals of Engineering and Natural Sciences, vol. 5, 2017.

[4] K. Almadhoni and S. Khan, "Evaluation of the Effective Thermal Properties of Aluminum Metal Matrix Composites Reinforced by Ceramic Particles," International Journal of Current Engineering 
and Technology, vol. 5, pp. 2884-2897, 2015.

[5] R. Ganesh, R. Subbiah, and K. Chandrasekaran, "Dry Sliding Wear Behavior of Powder Metallurgy Aluminium Matrix Composite," Materials Today: Proceedings, vol. 2, pp. 1441-1449, 2015.

[6] Saif S. Irhayyim, "Effect of Graphite/WC Additions on Physical, Mechanical and Wear Properties of Aluminum," Diyala journal of engineering sciences, vol. 4, pp. 72-86, 2017.

[7] M. R. Akbarpour, S. Alipour, F. L. Azar, and F. S. Torknik, "Microstructure and Hardness of Al-SiC Nanocomposite Fabricated through Powder Metallurgy Method," Indian Journal of Science and Technology, vol. 9, 2016.

[8] O. I. Sekunowo, S. I. Durowaye, and G. I. Lawal, "Synthesis and characterisation of iron millscale particles reinforced ceramic matrix composite," Journal of King Saud University - Engineering Sciences, 2018.

[9] A. Raturi, K. K. S. Mer, and P. K. Pant, "Synthesis and characterization of mechanical, tribological and micro structural behaviour of Al 7075 matrix reinforced with nano Al2O3 particles," Materials Today: Proceedings, vol. 4, pp. 2645-2658, 2017.

[10] F. M. Mahdi, R. N. Razooqi, and S. S. Irhayyim, "The Influence of Graphite Content and Milling Time on Hardness, Compressive Strength and Wear Volume of Copper - Graphite Composites Prepared Via Powder Metallurgy," Tikrit Journal of Engineering Sciences, vol. 24, pp. 47-54, Sep. 2017.

[11] S. Pradeep Devaneyan, R. Ganesh, and T. Senthilvelan, "On the Mechanical Properties of Hybrid Aluminium 7075 Matrix Composite Material Reinforced with $\mathrm{SiC}$ and TiC Produced by Powder Metallurgy Method," Indian Journal of Materials Science, vol. 2017, 2017.

[12] O. Inayatullah, "Condition Monitoring of the Uncoated Carbide Cutting Tool in Turning Process of the Aluminum Alloy 6061 via Vibration," Periodicals of Engineering and Natural Sciences, vol. 5, 2017.

[13] W. M. Daoush and O. A. Elkady, "Microstructure, physical properties and hardness of alumina short fibres/nickel matrix composites fabricated by powder technology," Journal of Composite Materials, vol. 48, pp. 3735-3746, 2014.

[14] B. K. A. Kumar, M. G. Ananthaprasad, and K. Gopala Krishna, "A Review on Corrosion Behavior of Nickel Matrix Composites," International Journal of Emerging Technology and Advanced Engineering, vol. 5, pp. 342-346, 2015.

[15] E. Akca, A. Gürsel, and G. Y1ldı, "Effects of Cooling Rate on Strength and Microstructure of Powder Metallurgy Superalloys," Periodicals of Engineering and Natural Sciences, vol. 5, 2017.

[16] E. Omrani, A. D. Moghadam, P. L. Menezes, and P. K. Rohatgi, "Influences of graphite reinforcement on the tribological properties of self-lubricating aluminum matrix composites for green tribology, sustainability, and energy efficiency-a review," The International Journal of Advanced Manufacturing Technology, vol. 83, pp. 325-346, 2016.

[17] A. D. Moghadam, B. F. Schultz, J. B. Ferguson, E. Omrani, P. K. Rohatgi, and N. Gupta, "Functional metal matrix composites: Self-lubricating, self-healing, and nanocomposites-an outlook," Jom, vol. 66, pp. 872-881, 2014.

[18] S. Şahin, N. Yüksel, H. Durmuş, and S. G. Irizalp, "Wear behavior of Al/SiC/graphite and Al/FeB/graphite hybrid composites," Materiali in Tehnologije, vol. 48, pp. 639-646, 2014.

[19] H. S. Humood, "Effect of Pressing Pressure on properties of Copper-10\% Graphite Composites Prepared by Powder Metallurgy Technique," Tikrit Journal of Engineering Sciences, vol. 24, pp. 28 34, 2017.

[20] A. Standard, "C373-88. Standard test method for water absorption, bulk density, apparent porosity and apparent specific gravity of fired whiteware products," ASTM International, West Conshohocken, PA, 2006.

[21] F. M. Mahdi, R. N. Razooqi, and S. S. Irhayyim, "Effect of Graphite Content and Milling Time on Physical Properties of Copper - Graphite Composites Prepared by Powder Metallurgy Route," Australian Journal of Basic and Applied Sciences, vol. 7, pp. 245-255, 2013.

[22] S. S. Irhayyim, S. Ahmed, and A. A. Annaz, "Mechanical performance of micro-Cu and nano-Ag reinforced Al-CNT composite prepared by powder metallurgy technique," Materials Research Express, vol. 6, p. 105071, Aug. 2019.

[23] A. Standard, "G99-05. Standard Test Method for Wear Testing with a Pin-on-Disk Apparatus," ASTM International, West Conshohocken, PA, 2010.

[24] H. R. Vitala, "Mechanical and Tribological Characterization Nitrided Al-7075/A12O3 Metal Matrix Composites," Periodicals of Engineering and Natural Sciences, vol. 6, pp. 64-70, 2018. 
[25] R. Dalmis, H. Cuvalci, A. Canakci, and O. Guler, "Investigation of graphite nano particle addition on the physical and mechanical properties of Za27 composites," Advanced Composites Letters, vol. 25, p. $096369351602500202,2016$.

[26] A. Zeren, "Effect of the graphite content on the tribological properties of hybrid Al/SiC/Gr composites processed by powder metallurgy," Industrial Lubrication and Tribology, vol. 67, pp. 262-268, 2015.

[27] P. Sundriyal and P. L. Sah, "Enhancement of Mechanical Properties of Graphite Particulate Aluminum Metal Matrix Composites by Magnesium Addition," Materials Today: Proceedings, vol. 4, pp. 94819486, 2017.

[28] S. N. Prashant, M. Nagaral, and V. Auradi, "Preparation And Evaluation Of Mechanical And Wear Properties Of Al6061 Reinforced With Graphite And Sic Particulate Metal Matrix Composites," International journal of mechanical engineering and robotics research, vol. 1, pp. 106-112, 2012.

[29] P. Sharma, K. Paliwal, R. K. Garg, S. Sharma, and D. Khanduja, "A study on wear behaviour of Al/6101/graphite composites," Journal of Asian Ceramic Societies, vol. 5, pp. 42-48, 2017.

[30] A. R. Ahmed, S. S. Irhayyim, and H. S. Hammood, "Effect of Yttrium Oxide Particles on the Mechanical Properties of Polymer Matrix Composite," IOP Conference Series: Materials Science and Engineering, vol. 454, p. 012036, Dec. 2018. 